NBER WORKING PAPER SERIES

\title{
PUBLIC FINANCE IN A NUTSHELL: A COBB DOUGLAS TEACHING TOOL FOR GENERAL EQUILIBRIUM TAX INCIDENCE AND EXCESS BURDEN
}

\author{
Don Fullerton \\ Chi L. Ta \\ Working Paper 23064 \\ http://www.nber.org/papers/w23064 \\ NATIONAL BUREAU OF ECONOMIC RESEARCH \\ 1050 Massachusetts Avenue \\ Cambridge, MA 02138 \\ January 2017
}

For comments and suggestions, we wish to thank Tengjiao Chen, Zhangliang Chen, Jonathan Meer, David Quigley, Juan Carlos Suárez Serrato, and students who solved our model as homework to provide suggestions. The views expressed herein are those of the authors and do not necessarily reflect the views of the National Bureau of Economic Research.

NBER working papers are circulated for discussion and comment purposes. They have not been peer-reviewed or been subject to the review by the NBER Board of Directors that accompanies official NBER publications.

(C) 2017 by Don Fullerton and Chi L. Ta. All rights reserved. Short sections of text, not to exceed two paragraphs, may be quoted without explicit permission provided that full credit, including () notice, is given to the source. 
Public Finance in a Nutshell: A Cobb Douglas Teaching Tool for General Equilibrium Tax

Incidence and Excess Burden

Don Fullerton and Chi L. Ta

NBER Working Paper No. 23064

January 2017

JEL No. A20,C63,C68,D04,D58,H21,H22,H23,H24,H25

\begin{abstract}
$\underline{\text { ABSTRACT }}$
To help first- or second-year graduate students in economics apply their theoretical training, this paper shows how to solve a simple and intuitive computable general equilibrium (CGE) model using a calculator. Because this simplified Harberger model uses Cobb Douglas functional forms for utility and production, one can solve for all input and output prices and quantities with no taxes and then solve for exact measures of output with a large tax change (not using derivatives). We then show how to solve simultaneously for capital and labor prices (incidence on the sources side of income), for both output prices (incidence on the uses side), for exact measures of overall welfare loss such as the equivalent variation, for excess burden and marginal excess burden, and for the effects on revenue in the form of a Laffer Curve.
\end{abstract}

\author{
Don Fullerton \\ Department of Finance \\ University of Illinois \\ 515 East Gregory Drive, BIF Box\#30 (MC520) \\ Champaign, IL 61820 \\ and NBER \\ dfullert@illinois.edu \\ Chi L. Ta \\ Department of Agricultural and Consumer Economics \\ University of Illinois \\ Urbana, IL 61801 \\ chita2@illinois.edu
}




\section{INTRODUCTION}

Undergraduate economics students can draw a partial equilibrium diagram of supply and demand in one market with one equilibrium price and quantity, and the good students understand the assumption that all other markets are unaffected. Most of them hear about the idea of general equilibrium, but they are told it is very complicated. First-year graduate students learn plenty of theory, but may not get many practical applications. Few wish to build computational general equilibrium (CGE) models because of the huge requirements of time, effort, data, and detail. Many who read descriptions of a complicated CGE model may think it seems like a "black box."

Yet many questions in economics cannot be addressed without a general equilibrium model. For example, the full distributional incidence of an output tax requires knowing its effects on prices in other markets - the return to capital, the wage rate, and effects on other output prices. In some cases, use of a general equilibrium (GE) model may reverse results from a partial equilibrium (PE) model. ${ }^{1}$ Similarly, both the magnitude and sign of the overall welfare effect of a tax in one market can depend on the magnitudes of pre-existing taxes in other markets.

This paper describes an extremely simple CGE model that can be solved on the "back of an envelope.” The paper can be read by a good undergraduate, and the model can be solved by a first- or second-year graduate student in economics. Our practical application illustrates the theoretical tools that graduate students learn in their first year, which are employed widely across all areas of public economics, including tax incidence, deadweight loss, marginal excess burden, and the effects of tax rate increases on tax revenue (the Laffer curve). These are major topics of a graduate course on taxation that might use various chapters in the Handbook of Public Economics. This short paper is not a substitute for that technical material, nor can it serve as a textbook for definitions of all of the concepts just listed. ${ }^{2}$ We mean this paper only to complement and supplement those chapters by providing a readily accessible example of all those textbook concepts in a single CGE model where each step shows how changes in one market affect other markets. ${ }^{3}$

We start with the Cobb Douglas example in McLure and Thirsk (M\&T), published in

\footnotetext{
${ }^{1}$ Mas-Colell, Whinston, and Green (1995) describe an example from Bradford (1978) of a local tax on mobile labor where the burden is on local profits in a PE model but on labor nationwide in a GE model.

${ }^{2}$ See the Handbook chapters on "Tax Incidence" (Fullerton and Metcalf, 2002) and "Taxation and Economic Efficiency” (Auerbach and Hines, 2002). For textbook definitions, see Mas-Colell, Whinston, and Green (1995).

${ }^{3}$ For more complete discussions of CGE models in taxation, see Shoven and Whalley (1992) and Zodrow and Diamond (2013).
} 
1975 in the National Tax Journal, which one of us read in 1975 as a first-year graduate student — and has used as a teaching tool since then while thinking of various "improvements." The other of us just started her first year of graduate school, undertook all of the calculations for this paper, and also finds the M\&T article very helpful. We hope that our paper will be widely read and employed in teaching. Our goal is identical to that stated by M\&T: "Since our aim is pedagogical we present no new analytical results but, instead, try to disseminate established ones to a wider readership” (M\&T, 1975, p. 1).

No calculation in this paper requires a computer, though a calculator may be useful. The reader can see exactly how to calculate each of these many concepts, all in less than half the length of the paper by M\&T. Our paper can be used either of two ways. It can be assigned to students to read and replicate, or alternatively, our Appendix provides a homework assignment that can be handed out to graduate students before they are assigned this paper as the answer key.

For a pedagogical paper, however, we make several contributions. The first is simply to re-introduce this intuitive and helpful example, which has fallen into dis-use. Second, we improve upon the approximations employed in that paper by showing equally simple ways to solve for the exact equilibrium output and price of each commodity.

Third, we show that the Harberger (1964) triangle used to calculate deadweight loss is also an unnecessary approximation, because the same model can easily be used to calculate "exact” measures of welfare loss. To do this, we use the Cobb Douglas functions to solve for indirect utility, the expenditure function, and the equivalent variation measure of excess burden. Our exact measure of deadweight loss is almost 20 percent larger than the approximation employed for the same numerical example in M\&T.

Fourth, we also calculate the corresponding measure of marginal excess burden. For our example with a 30 percent tax on one output, the average excess burden (total excess burden divided by total revenue) is 8.7 cents on the dollar, while the marginal excess burden (the change in excess burden divided by the change in revenue) is 21 cents. We discuss the implications of this difference.

Fifth, we use the same model to calculate tax revenue resulting from each tax rate from 1 to 99 percent. These calculations yield the Laffer curve for the excise tax we analyze.

Section II presents a brief review of the simplified Harberger model, while Section III shows the solutions of M\&T (1975). Section IV then extends their example by showing how to find exact solutions for outputs, prices, and tax incidence. Section V derives an exact measure of 
excess burden, while Section VI shows how to calculate it. Section VII defines and calculates marginal excess burden, while Section VIII plots the Laffer curve. Section IX concludes.

\section{A REVIEW OF THE SIMPLIFIED HARBERGER MODEL}

The corporate income tax might directly reduce the net return to investment in the corporate sector, but reallocation of capital and labor might affect non-corporate returns, wages, and output prices. To study the incidence of the corporate tax, Harberger (1962) assumes a closed economy with a corporate sector producing one output $(\boldsymbol{X})$ and a non-corporate sector producing a different output $(Y)$. The model includes two factor inputs, fixed factor supplies, full employment, constant returns to scale, and all the "perfect” assumptions: perfect certainty, perfect competition, perfect factor mobility, and perfect information. Each output is produced using capital and labor in a general function [e.g., $\left.X=F\left(K_{X}, L_{X}\right)\right]$ allowing for any elasticity of substitution between inputs. Pure profits are zero because of perfect competition, but the tax applies to the normal return to owners of capital in the corporate sector $(\boldsymbol{X})$, so Harberger models it as a tax at rate $t_{K X}$ on use of $K_{X}$. He differentiates all equations to linearize the model in derivatives, and then solves $N$ linear equations for $N$ unknowns (the change in each quantity and price for a change in tax). A disadvantage is that this method is strictly valid only for a small tax (or small change in tax). Harberger solves for the change in the economy-wide return to capital relative to the wage rate (incidence on the sources side of income).

A major change by M\&T (1975) is to use Cobb Douglas functions, which has both advantages and disadvantages. The main limitation is that all elasticities of substitution are 1.0, which obscures the fact that burdens on labor or capital can depend on each elasticity (though incidence still depends on other parameters, as shown below). The main advantage of CobbDouglas forms, however, is that the model can be solved without taking derivatives. The equations are solved directly, with tax rates of any size, for equilibrium levels of prices and quantities. ${ }^{4}$ We solve below for equilibrium with no taxes, and then with a large tax rate, allowing exact comparisons of prices, quantities, and welfare. We also use the model to solve for effects of a tax on one output $\left(t_{X}\right)$, and to solve for both factor prices and output prices (incidence on the uses side of income).

\footnotetext{
${ }^{4}$ Kimbell and Harrison (1986) show how to solve analytically for levels of prices and quantities before and after a large tax change using a general equilibrium model with constant elasticity of substitution (CES) utility and production functions. Cobb-Douglas functions are used here because they are simpler to solve on the back of an envelope; they are a special case of CES functions where the elasticities of substitution are all 1.0.
} 
The model can be useful to study taxation of any two sectors (e.g., housing or agricultural output versus manufacturing). It can represent any two inputs (e.g., polluting inputs versus nonpolluting inputs). For example, the M\&T version of the Harberger model has two sectors $(X, Y)$, each with Cobb-Douglas production. In their numerical example ( $\alpha=\mathbf{0 . 6}$ and $\beta=0.2$ ), we have

$$
X=A K_{X}^{\alpha} L_{X}^{1-\alpha}=A K_{X}^{0.6} L_{X}^{0.4} \text { and } Y=B K_{Y}^{\beta} L_{Y}^{1-\beta}=B K_{Y}^{0.2} L_{Y}^{0.8}
$$

with constant parameters $\boldsymbol{A}, \boldsymbol{B}, \boldsymbol{\alpha}$, and $\boldsymbol{\beta}$. Inputs $K_{\boldsymbol{X}}$ and $L_{\boldsymbol{X}}$ denote capital and labor used in the corporate sector, $X$, while $K_{Y}$ and $L_{Y}$ are the analogous factors used in the non-corporate sector $Y$.

Because total factor supplies are fixed in this static model, households have no savings decision and no labor supply decision. The economy-wide resource constraints are

$$
K_{X}+K_{Y}=\bar{K} \text { and } L_{X}+L_{Y}=\bar{L} \text {. }
$$

M\&T also assume a Cobb-Douglas utility function, where $\gamma=\mathbf{0 . 5}$ in their example

$$
U=X^{\gamma} Y^{1-\gamma}=X^{0.5} Y^{0.5}
$$

Many identical households choose goods $X$ and $Y$ to maximize utility subject to income $I$. The budget constraint for such spending is $I=X P_{X}+Y P_{Y}$, where $P_{X}$ and $P_{Y}$ are the prices faced by consumers (gross of any tax). The resulting demand for $X$ is just $X=\gamma I / P_{X}$ (which students can derive as an exercise). It is a very simple form of demand with the key properties that demand for $X$ rises with income $I$, and slopes down with respect to price $\boldsymbol{P}_{\boldsymbol{X}}$ (although all crossprice effects are zero). A slight re-arrangement of demands shows that expenditure, $X P_{X}$, is a fixed fraction of income, $\gamma I$ [and $\left.Y P_{Y}=(1-\gamma) I\right]$.

Since only relative prices matter, most general equilibrium models solve for all prices relative to one "numeraire” good or factor with a fixed price. Instead, M\&T anchor the overall price level by assuming that nominal national income is fixed $(I=\bar{I})$. Thus, if a tax on $X$ raises the consumer price $P_{X}$, then all quantities adjust and $P_{Y}$ must fall so that the total $I=X P_{X}+Y P_{Y}$ is unchanged. In their numerical example, $I$ is fixed at $\bar{I}=2,400$ (which could be billions or trillions, depending on the size of the economy, in dollars or any other currency). Thus we have

$$
X P_{X}=\gamma I=0.5 \times 2,400=1,200,
$$




$$
Y P_{Y}=(1-\gamma) I=(1-0.5) \times 2,400=1,200 .
$$

On the other side of the ledger, income $I$ includes receipts from factor endowments and from the government's transfer of all tax revenue back to households as a lump-sum rebate, $R$. Thus, $I=\bar{K} P_{K}+\bar{L} P_{L}+R$, where $P_{K}$ is the net-of-tax rental price for capital, and $P_{L}$ is the net-oftax wage. ${ }^{5}$ For consistency, every price is a price faced by households: they receive net-of-tax factor prices $\left(\boldsymbol{P}_{\boldsymbol{K}}\right.$ and $\boldsymbol{P}_{\boldsymbol{L}}$ ) and pay gross-of-tax output prices $\left(\boldsymbol{P}_{\boldsymbol{X}}\right.$ and $\boldsymbol{P}_{\boldsymbol{Y}}$ ). Thus, a tax on output of $X$ means that firms receive $X P_{X}\left(1-t_{X}\right)$, where $t_{X}$ is the tax as a fraction of the consumers' gross price. The corporate income tax is modeled as a tax on capital in the corporate sector, $\boldsymbol{X}$, so a firm's cost of capital is $P_{K}\left(1+t_{K X}\right)$, where $t_{K X}$ is the tax as a fraction of a household's net return. Other taxes could be modeled analogously, but we use just those two for simplicity.

Firms choose inputs $K$ and $L$ to maximize profits subject to their production function, and the Cobb Douglas forms yield very simple factor demands. Firms in $X$ always use $\boldsymbol{\alpha}$ of net sales revenue, $X P_{X}\left(1-t_{X}\right)$, to buy units of capital, $K_{X}$, each of which costs $P_{K}\left(1+t_{K X}\right)$. In general,

$$
\begin{aligned}
& K_{X} P_{K}\left(1+t_{K X}\right)=\alpha X P_{X}\left(1-t_{X}\right), K_{Y} P_{K}=\beta Y P_{Y}, \\
& L_{X} P_{L}=(1-\alpha) X P_{X}\left(1-t_{X}\right), \text { and } L_{Y} P_{L}=(1-\beta) Y P_{Y}
\end{aligned}
$$

These equations hold in equilibrium for any tax rates and parameters. Thus, one can set $\boldsymbol{t}_{\boldsymbol{X}}=\mathbf{0}$ to find the incidence of just the corporate income tax $\left(t_{K X}\right)$. Alternatively, we can set $t_{K X}=\mathbf{0}$ to solve for effects of the tax on output, $t_{X}$. In the latter case, it helps to use the specific numerical example.

In the initial equilibrium where all tax rates are zero, M\&T employ the "unit convention" by defining a unit of each good or factor as the amount that costs one dollar. Then $P_{K}^{0}=P_{L}^{0}=P_{X}^{0}=P_{Y}^{0}=1$, where the superscript “ 0 ” indicates the initial no-tax equilibrium. Equations (4) and (5) state that $X P_{X}=Y P_{Y}=1200$, so the initial quantities are $X^{0}=Y^{0}=1200$. Then, in the initial equilibrium with $t_{X}=t_{K X}=0$, (6) and (7) imply

\footnotetext{
${ }^{5}$ For calculating equilibrium prices and quantities, our assumption about the return of revenue is equivalent to the assumption in M\&T that government spending on $\boldsymbol{X}$ and $\boldsymbol{Y}$ is in the same proportion as consumers.
} 
(8) $\quad P_{K}^{0} K_{X}^{0}=\alpha X^{0} P_{X}^{0}=0.6 \times 1,200=720$,

(9) $\quad P_{L}^{0} L_{X}^{0}=(1-\alpha) X^{0} P_{X}^{0}=0.4 \times 1,200=480$,

$$
P_{K}^{0} K_{Y}^{0}=\beta Y^{0} P_{Y}^{0}=0.2 \times 1,200=240,
$$

$$
P_{L}^{0} L_{Y}^{0}=(1-\beta) Y^{0} P_{Y}^{0}=0.8 \times 1,200=960 \text {. }
$$

With $P_{K}^{0}=P_{L}^{0}=1$, these equations yield the entire set of initial quantities shown in Table 1 .

Table 1

Initial Quantity Allocations

\begin{tabular}{lll}
\hline$L_{X}^{0}=480$ & $L_{Y}^{0}=960$ & $\bar{L}=1,440$ \\
$K_{X}^{0}=720$ & $K_{Y}^{0}=240$ & $\bar{K}=960$ \\
$X^{0}=1,200$ & $Y^{0}=1,200$ & $\bar{I}=2,400$
\end{tabular}

That is, for the Cobb-Douglas model with the assumed utility function and production function parameters that yield the calculated initial equilibrium outcomes, the total labor endowment must be 1,440 , and the total capital endowment must be 960 .

\section{SOLUTIONS OF MCLURE AND THIRSK (1975)}

The simplified Harberger model in (6) and (7) can be used to find the incidence of the corporate income tax as general result (without using the particular numerical example). Set $t_{X}=\mathbf{0}$ to study $t_{K X}$. Expenditure $X P_{X}$ in this Cobb-Douglas model is a fixed fraction of income, $\gamma I$, so the sum of the two equations in (6) is

$$
K_{X} P_{K}\left(1+t_{K X}\right)+K_{Y} P_{K}=\alpha X P_{X}+\beta Y P_{Y}=\alpha \gamma I+\beta(1-\gamma) I=\text { constant }
$$

Rearranging yields $\bar{K} P_{K}=$ constant $-K_{X} P_{K} t_{K X}$, which implies that any corporate income tax reduces capital income $\left(\bar{K} P_{K}\right)$ by precisely the full amount of the tax $\left(K_{X} P_{K} t_{K X}\right)$. That is, capital always bears the full burden of this tax, on the sources side of income. ${ }^{6}$ The sum of the two equations in (7) is $\bar{L} P_{L}=(1-\alpha) \gamma I+(1-\beta)(1-\gamma) I$, which is also a constant, so labor bears no

\footnotetext{
${ }^{6}$ This result was proven by Harberger (1962) in his proposition (9) for the Cobb Douglas special case. For intuition, note that each sector's gross-of-tax spending on capital is a constant fraction of a fixed income.
} 
burden of the corporate income tax (on the sources side). In a moment we show how to calculate the new higher price of $X$ and new lower price of $Y$, but if all consumers spend the same fraction of income on $X$, then this tax has no differential effects on the uses side of incidence.

Using the numerical example, M\&T then consider a 30 percent tax on $X\left(t_{X}=\mathbf{0 . 3 0}\right.$ with $\left.t_{K X}=0\right)$. All initial prices are 1.0, and Table 1 provides all quantities in the no-tax equilibrium. We now need to solve simultaneous equations for a set of ten unknowns: the four new prices ( $\boldsymbol{P}_{\boldsymbol{X}}$ $, \boldsymbol{P}_{Y}, \boldsymbol{P}_{\boldsymbol{K}}, \boldsymbol{P}_{L}$ ) and the six new quantities (the variables in the first two columns of Table 1).

This calculation proceeds as follows, using primes to denote new prices and quantities. Expenditure on $X$ will still be equal to the share $\gamma$ of income, $X^{\prime} P_{X}{ }^{\prime}=\gamma I=1,200$, so firms producing $X$ pay tax of $X^{\prime} P_{X}{ }^{\prime} t_{X}=360$. Equations (6) and (7) hold for any tax rates, so

$$
\begin{aligned}
& K_{X}{ }^{\prime} P_{K}{ }^{\prime}=\alpha X^{\prime} P_{X}{ }^{\prime}\left(1-t_{X}\right)=720 \times 0.70=504, K_{Y}{ }^{\prime} P_{K}{ }^{\prime}=\beta Y^{\prime} P_{Y}{ }^{\prime}=240 \\
& L_{X}{ }^{\prime} P_{L}^{\prime}=(1-\alpha) X^{\prime} P_{X}{ }^{\prime}\left(1-t_{X}\right)=480 \times 0.70=336, L_{Y}{ }^{\prime} P_{L}{ }^{\prime}=(1-\beta) Y^{\prime} P_{Y}{ }^{\prime}=960
\end{aligned}
$$

The sum of capital incomes in the two equations in (12) is $\bar{K} P_{K}{ }^{\prime}=504+240=744$, compared to original capital income of $\bar{K} P_{K}^{0}=\mathbf{9 6 0}$. Thus, capital income has fallen by 216, and owners of capital bear a fraction of the tax burden on the sources side that is $216 / 360=0.60$. Labor income in (13) falls from 1440 to $\bar{L} P_{L}{ }^{\prime}=336+960=1,296$, so workers' fraction of the tax burden is $144 / 360=0.40$. Moreover, those numbers can also be used to solve for the new factor returns. Since $\bar{K} P_{K}{ }^{\prime}=744$, and $\bar{K}=960$ (in Table 1 ), we have $P_{K}{ }^{\prime}=744 / 960=0.775$ (a 22.5 percent fall in the net rate of return). In contrast, $\bar{L} P_{L}{ }^{\prime}=1,296$, so $P_{L}{ }^{\prime}$ is $1,296 / 1,440=0.90$ (only a 10 percent fall in the wage rate).

Why does capital bear a heavier relative burden from this tax on output? The answer is that the taxed sector is relatively capital intensive. The production function $X=A K_{X}^{0.6} L_{X}^{0.4}$ implies that firms in $X$ spend 60 percent of sales revenue to buy capital, while $Y=B K_{Y}^{02} L_{Y}^{0.8}$ implies that firms there spend only 20 percent of sales revenue to buy capital. The new tax on $X$ shrinks production of $\boldsymbol{X}$ and thus particularly reduces aggregate demand for capital. 
The new factor returns allow for the calculation of all new factor allocations: ${ }^{7}$

$$
\begin{aligned}
& K_{X}{ }^{\prime}=\frac{K_{X}{ }^{\prime} P_{K}{ }^{\prime}}{P_{K}{ }^{\prime}}=\frac{504}{0.775}=650.32258, K_{Y}{ }^{\prime}=\frac{K_{Y}{ }^{\prime} P_{K}{ }^{\prime}}{P_{K}{ }^{\prime}}=\frac{240}{0.775}=309.67742, \\
& L_{X}{ }^{\prime}=\frac{L_{X}{ }^{\prime} P_{L}{ }^{\prime}}{P_{L}{ }^{\prime}}=\frac{336}{0.9}=373.33333, L_{Y}{ }^{\prime}=\frac{L_{Y}{ }^{\prime} P_{L}{ }^{\prime}}{P_{L}{ }^{\prime}}=\frac{960}{0.9}=1,066.66667 .
\end{aligned}
$$

Notice that the two capital quantities in the first row still add to $\bar{K}=960$, while the two labor quantities in the second row still add to $\bar{L}=1,440$ (Table 1 ). Since factors are perfectly mobile between sectors, the 30 percent tax on good $\boldsymbol{X}$ induces both capital and labor to move from the taxed sector $\boldsymbol{X}$ to the untaxed sector $\boldsymbol{Y}$ until each has a net return that is equalized across sectors. Because $X$ is capital intensive, $P_{K}$ ' has to fall enough for firms in $Y$ to re-employ all that capital.

\section{EXACT SOLUTIONS FOR OUTPUT, PRICE AND TAX INCIDENCE}

All calculations so far have been taken directly from M\&T, but we now turn to our various improvements to the Cobb Douglas teaching tool. First, Harberger (1962) solved only for factor prices, but the same model could easily have also been used to solve for output prices. Calculations so far show that $X^{\prime} P_{X}{ }^{\prime}=\gamma I=1,200$ but do not determine $X^{\prime}$ or $P_{X}{ }^{\prime}$ separately. To calculate $X^{\prime}$, M\&T differentiate the production function to obtain the change in output as a linear function of the changes to inputs. ${ }^{8}$ This approximation procedure is appropriate for a small tax, but not for a large tax. Moreover, approximation is entirely unnecessary, since we can calculate exact quantities. We know all initial equilibrium quantities in production from Table 1 , so we use $X=A K_{X}^{0.6} L_{X}^{0.4}$ to "solve backwards" for what the $A$ parameter must have been to yield those outcomes, or $A=X^{0} /\left[\left(K_{X}^{0}\right)^{0.6}\left(L_{X}^{0}\right)^{0.4}\right]=1.96013$, and similarly, $B=Y^{0} /\left[\left(K_{Y}^{0}\right)^{0.2}\left(L_{Y}^{0}\right)^{0.8}\right]=1.69438$. Using these parameters and the new factor allocations, we have $X^{\prime}=1.96013 \times 650.32258^{0.6} \times 373.33333^{0.4}=1,020.94$, $Y^{\prime}=1.64938 \times 309.67742^{0.2} \times 1,066.66667^{0.8}=1,373.81$. Finally, these solutions for output

\footnotetext{
${ }^{7}$ For subsequent steps, it helps to keep as many digits as possible (as is done when using Excel for each step).

${ }^{8}$ Using $\Delta X / X=\alpha\left(\Delta K_{X} / K_{X}\right)+(1-\alpha)\left(\Delta L_{X} / L_{X}\right)$ and inserting the parameter values and quantities above, M\&T get $(0.6)(-69.667) / 720+(0.4)(-106.667) / 480=-0.14695$.
} 
enable exact calculation of consumer prices $P_{X}{ }^{\prime}=X^{\prime} P_{X}{ }^{\prime} / X^{\prime}=1,200 / 1,020.94=1.17538$ and $P_{Y}{ }^{\prime}=Y^{\prime} P_{Y}{ }^{\prime} / Y^{\prime}=1,200 / 1,373.81=0.87348$

In Table 2, Panel A shows all the initial equilibrium prices and quantities (in the column labeled $t_{X}=\mathbf{0 . 0}$ ), and new equilibrium prices and quantities (in the column labeled $t_{X}=0.30$ ). Later sections derive the numbers in Panel B and in the entire last column.

\section{Table 2}

Summary of Key Variables

\begin{tabular}{|c|c|c|c|c|}
\hline $\begin{array}{c}(1) \\
\text { Variable }\end{array}$ & $\begin{array}{c}(2) \\
\text { Definition }\end{array}$ & $\begin{array}{c}(3) \\
\text { Value at } \\
\boldsymbol{t}_{\boldsymbol{x}}=\mathbf{0 . 0 0}\end{array}$ & $\begin{array}{c}(4) \\
\text { Value at } \\
t_{X}=\mathbf{0 . 3 0}\end{array}$ & $\begin{array}{c}(5) \\
\text { Value at } \\
\boldsymbol{t}_{\boldsymbol{X}}=\mathbf{0 . 3 1}\end{array}$ \\
\hline \multicolumn{5}{|c|}{ Panel A: Allocations and Prices } \\
\hline$K_{X}$ & Capital in production of $\boldsymbol{X}$ & 720.0 & 650.323 & 674.296 \\
\hline$L_{X}$ & Labor in production of $\boldsymbol{X}$ & 480.0 & 373.333 & 369.368 \\
\hline$K_{Y}$ & Capital in production of $Y$ & 240.0 & 309.677 & 312.704 \\
\hline$L_{Y}$ & Labor in production of $Y$ & 960.0 & $1,066.67$ & $1,070.63$ \\
\hline$X$ & Output of $X$ & $1,200.0$ & $1,020.94$ & $1,013.75$ \\
\hline$Y$ & Output of $Y$ & $1,200.0$ & $1,373.81$ & $1,380.58$ \\
\hline$P_{K}$ & Net return to capital & 1.00000 & 0.77500 & 0.76750 \\
\hline$P_{L}$ & Net wage rate & 1.00000 & 0.90000 & 0.89667 \\
\hline$P_{X}$ & Consumer price of $\boldsymbol{X}$ & 1.00000 & 1.17538 & 1.18372 \\
\hline$P_{Y}$ & Consumer price of $Y$ & 1.00000 & 0.87348 & 0.86920 \\
\hline \multicolumn{5}{|c|}{ Panel B: Exact Measures of Welfare } \\
\hline $\bar{P}$ & Price index over both outputs & 2.00000 & 2.02650 & 2.02869 \\
\hline$U$ & Utility & $1,200.0$ & $1,184.306$ & $1,183.030$ \\
\hline$E B$ & Excess Burden & 0.000 & 31.387 & 33.934 \\
\hline$R$ & Revenue (equal to Rebate) & 0.0 & 360.000 & 372.000 \\
\hline$A E B$ & Average Excess Burden $(E B / R)$ & & 0.08719 & 0.09124 \\
\hline$M E B$ & $\begin{array}{l}\text { Marginal Excess Burden (change in } \\
E B \text { per additional dollar of revenue) }\end{array}$ & & & 0.21271 \\
\hline
\end{tabular}

The new output prices can be used to calculate burdens on the uses side, but such calculations are not interesting if all consumers spend their income in the same proportions. To discuss burdens on the uses side, M\&T suppose that laborers spend a relatively large fraction of 
income on $Y$, while capitalists spend a relatively large fraction on $X$. Here, we note that workers and savers are not really different people. Actual households are heterogeneous, each with its own mix of wages, capital income, and commodity preferences. Therefore, we merely calculate output prices based on the model above — assuming that demand by identical households adequately represents aggregate demand by the actual diverse millions of households. Then we observe that prices can be used to infer burdens on both the sources side and the uses side for any individual household $\boldsymbol{i}$ that differs from the average in terms of endowments $\left(K_{i} / L_{i}\right)$ or preferences $\left(\gamma_{i}\right)$.

\section{EXACT MEASURES OF WELFARE LOSS}

We now compute exact welfare measures, using the expenditure function to obtain excess burden. First, the demand functions $X=\gamma I / P_{X}$ and $Y=(1-\gamma) I / P_{X}$ can be substituted into the utility function $\left(U=X^{\gamma} Y^{\mathbf{1}-\gamma}\right)$, to obtain the indirect utility function

$$
V\left(P_{X}, P_{Y}, I\right)=\left(\frac{\gamma I}{P_{X}}\right)^{\gamma}\left[\frac{(1-\gamma) I}{P_{Y}}\right]^{1-\gamma}=\frac{I^{\gamma} I^{1-\gamma}}{\left(\frac{P_{X}}{\gamma}\right)^{\gamma}\left(\frac{P_{Y}}{1-\gamma}\right)^{1-\gamma}}=\frac{I}{\bar{P}},
$$

where $\bar{P}=\left(P_{X} / \gamma\right)^{\gamma}\left(P_{Y} /(1-\gamma)\right)^{1-\gamma}$ is the "ideal” price index, a function of $P_{X}$ and $P_{Y}$. Inverting the indirect utility function to obtain the expenditure function yields

$$
I=E(\bar{P}, U)=U \times \bar{P} .
$$

This expression makes clear that $\overline{\boldsymbol{P}}$ is essentially the price paid per unit of utility (per "util”). ${ }^{9}$ With these convenient Cobb Douglas forms, (15) simply indicates that total expenditure is price times quantity.

The expenditure function shows the income required to reach the utility level $\boldsymbol{U}$, given the price $\overline{\boldsymbol{P}}$, so it can be used to derive a "money metric” measure of the welfare impact of a price change. We use the equivalent variation $(E V)$, defined as the change in wealth at old prices that would be equivalent in terms of utility to the price change. In the case with fixed income, Mas-Colell, Whinston, and Green (1995) show EV can be measured as

$$
E V=E\left(\bar{P}^{0}, U^{\prime}\right)-E\left(\bar{P}^{\prime}, U^{\prime}\right)=E\left(\bar{P}^{0}, U^{\prime}\right)-\bar{I}=E\left(\bar{P}^{0}, U^{\prime}\right)-E\left(\bar{P}^{0}, U^{0}\right)
$$

\footnotetext{
${ }^{9}$ The ideal price index is the Lagrange multiplier when minimizing expenditure for a given level of utility.
} 
where $\bar{I}$ is fixed income, $\bar{P}^{0}$ is the old price, and $\bar{P}^{\prime}$ is the new price. In the Cobb Douglas case,

$$
E V=\bar{P}^{0} \times U^{\prime}-\bar{P}^{0} \times U^{0}=\bar{P}^{0} \times\left(U^{\prime}-U^{0}\right) .
$$

The $E V$ uses old prices to value the change in utility. ${ }^{10}$ Since the tax reduces welfare, this $E V$ is negative, so we use $-\boldsymbol{E V}$ as a positive measure of the tax burden. When this burden on taxpayers exceeds revenue collected by government, the subtraction of revenue yields “excess burden” (Auerbach and Hines, 2002). In our case, however, we consider a revenue-neutral policy package with a distorting tax $\left(t_{X}\right)$ where all revenue is returned to consumers via lump-sum rebate $(R)$. Net revenue is zero, and the net loss to consumers is the excess burden $(E B)$

$$
E B \equiv-E V=\bar{P}^{0} \times\left(U^{0}-U^{\prime}\right)
$$

Interestingly, this exact measure of welfare change is simpler than the approximation. ${ }^{11}$

\section{EXACT SOLUTION FOR EXCESS BURDEN}

Next, we use the numerical example above to calculate the initial and post-tax level of utility and price index, for use in equation (18) to obtain excess burden. The price index from (14) is $\bar{P} \equiv\left(P_{X} / \gamma\right)^{\gamma}\left(P_{Y} /(1-\gamma)\right)^{1-\gamma}$, where $\gamma$ is 0.5 , and $P_{X}^{o}=P_{Y}^{0}=1$. Thus the untaxed equilibrium price index equals $\bar{P}^{0}=2^{0.5} 2^{0.5}=2$. The two utility levels from (3) are $U^{0}=X^{0.5} Y^{05}=1,200^{0.5} \times 1,200^{0.5}=1,200$ and $U^{\prime}=\left(X^{\prime}\right)^{0.5}\left(Y^{\prime}\right)^{0.5}=1,020.94^{0.5} \times 1,373.81^{0.5}=1,184.31$.

Thus, the excess burden of a 30 percent tax on good $\boldsymbol{X}$ is

$$
E B_{t_{x}=0.30}=\bar{P}^{0} \times\left(U^{0}-U^{\prime}\right)=2 \times(1,200-1,184.31)=31.387
$$

\footnotetext{
${ }^{10}$ Analogously, the Compensating Variation $(\boldsymbol{C V})$ uses new prices to value the change in utility, $\boldsymbol{C V}=\overline{\boldsymbol{P}}^{\mathrm{r}}\left(\boldsymbol{U}^{\mathbf{r}}-\boldsymbol{U}^{0}\right)$. The advantage of the $E V$ measure is that welfare effects of different taxes can be compared using the same prices (Kay, 1980).

${ }^{11}$ For sub-group $\boldsymbol{i}$ that buys new quantities $\boldsymbol{X}_{\boldsymbol{i}}{ }^{\mathbf{}}$ and $\boldsymbol{Y}_{\boldsymbol{i}}{ }^{\mathbf{1}}$, M\&T calculate burden on the uses side as $-\left(X_{i}{ }^{\prime} \Delta P_{X}+Y_{i}{ }^{\prime} \Delta P_{Y}\right)$, an approximation for the change in real income. This Paasche index formula uses new quantities as weights, whereas the Laspeyres index uses old quantities. M\&T note "Both are only approximations to the true welfare loss, and in fact bracket it” (M\&T, p. 10). They also calculate excess burden of the 30 percent tax on $X$ by use of a Harberger (1964) triangle formula, $0.5 \Delta P_{X} \Lambda X+0.5 \Delta P_{Y} \wedge Y$, which itself is an approximation of the true welfare cost. M\&T calculate it using their approximations for changes in prices and outputs, and they get excess burden of 26.50 (used below).
} 
This measure is almost 20 percent more than the approximation by M\&T mentioned above. ${ }^{12}$

How big is this welfare loss? Average excess burden $(A E B)$ can be defined as the total welfare loss from the tax divided by the total revenue collected by the government. Alternatively, it can be interpreted as the welfare gain from replacing the whole distorting tax with a nondistorting lump sum tax. In our example, the tax of 30 percent levied on good $X$ yields 360 of tax revenue, so the average excess burden per dollar of tax revenue is

$$
A E B \equiv \frac{E B}{R}=\frac{31.387}{360}=0.08719,
$$

which means that consumers on average lose 8.7 cents per dollar collected by government.

As an aside, note that the excess burden of a tax can be negative, especially in a secondbest world with pollution externalities or other pre-existing tax distortions. For example, suppose the 30 percent tax on $X$ already applies, and the government contemplates an additional 30 percent tax on $Y$. In this model, a common tax on both commodities is a lump-sum tax, so the extra 30 percent tax on $Y$ adds an excess burden of -31.387 (because it eliminates the $E B$ of the tax on $X)$.

\section{MARGINAL EXCESS BURDEN}

Policy discussions do not normally consider the addition or elimination of an entire tax system. More common is debate about whether to increase or decrease a particular tax rate. In fact, policymakers can take a step towards improving economic efficiency if they reduce an egregious tax, even with a revenue-neutral increase in a less-distorting tax. For these discussions, a highly useful measure is the marginal excess burden $(M E B)$ of a small change in a tax rate, defined as the change in excess burden per additional dollar of tax revenue. ${ }^{13}$

We therefore consider a small increase in the tax on $\boldsymbol{X}$ discussed above, from 30 to 31 percent. Following the same steps shown in previous sections, we obtain a set of new outcomes for $t_{X}=\mathbf{0 . 3 1}$, with the resulting prices and quantities indicated by a double prime. The last column of Table 2 above lists all of the key outcomes. By assumption, income is still fixed at 2,400, of which half is spent on good $X$, so, $P_{X}{ }^{\prime \prime} X "=1,200$. Then, the new revenue is 0.31

\footnotetext{
${ }^{12}$ The M\&T approximation is 26.50 (M\&T, 1975, footnote 10 ). The $C V$ is $2.0265 \times(\mathbf{1}, \mathbf{2 0 0}-\mathbf{1 , 1 8 4 . 3 1})=\mathbf{3 1 . 7 9 6}$, which is very close to the $\boldsymbol{E V}$, so the "approximation" does not lie between the two "exact" measures of welfare change.

${ }^{13}$ Mayshar (1990) and Auerbach and Hines (2002) provide many alternative definitions.
} 
times 1,200 , and the change in revenue is 0.01 times 1,200 , which equals 12 . The change in excess burden is the new excess burden minus the previous excess burden

$$
\Delta E B=E B_{t_{x}=0.31}-E B_{t_{x}=0.30}=\bar{P}^{0}\left(U^{\prime}-U^{\prime \prime}\right)
$$

This concept calculates the money metric change in utility from a small increase in the tax rate. For comparability, it is valued in the same initial dollars as our other measures above. Given the steps provided in detail above, we leave it as an exercise for the reader to calculate each new price and quantity in the last column of Table 2. Using those quantities ( $X^{\prime \prime}$ and $Y^{\prime \prime}$ ), the new utility level is $U^{\prime \prime}=\left(X^{\prime \prime}\right)^{0.5}\left(Y^{\prime \prime}\right)^{0.5}=1,013.750^{0.5} \times 1,380.577^{0.5}=1,183.030$.

We substitute these values into (20) to obtain the change in excess burden, $\Delta E B=2.55247$ (e.g., billions of dollars, or trillions of some other currency). Then, the marginal excess burden is this change in excess burden as a fraction of the change in revenue

$$
M E B \equiv \frac{\Delta E B}{\Delta R}=\frac{2.55247}{12}=0.21271
$$

The interpretation is that consumers lose an extra 21 cents per marginal dollar collected by the government. Notice that the marginal excess burden substantially exceeds the average excess burden (8.7 cents), as it rises more than proportionately with the tax rate. The intuition is based on the original Harberger (1964) triangle approximation, where the area of the triangle depends on the square of the tax rate - doubling the tax rate quadruples the excess burden.

\section{LAFFER CURVE}

A plot of revenue against the tax rate is called a Laffer curve, normally drawn as a humpshaped curve where revenue starts at zero, rises with the tax rate up to some revenuemaximizing tax rate, and then falls with further increases in the tax rate. The logic is that revenue must fall back to zero with a 100 percent tax on income, as nobody would bother to earn taxable income. Further intuition is that marginal excess burden rises disproportionately with the tax rate, discouraging any taxed activity - up to the peak of the Laffer curve where $M E B \equiv \triangle E B / \triangle R$ becomes infinite (when further increases in the tax rate yield zero additional revenue in the denominator).

Using our same example from above, we plot a Laffer Curve for the commodity tax, $t_{X}$. Our example is similar to one used by Gahvari (1988), where utility is a function of three goods - (1) a good produced using taxed labor (analogous our taxed good $\boldsymbol{X}$ ), (2) untaxed leisure (analogous to our untaxed good $Y$ ), and (3) a government-provided public good (which is 
separable in the utility function). Laffer effects arise because of substitution from the taxed to the untaxed good, but Gahvari points out that if government keeps the revenue then the income effect on the untaxed good works in the opposite direction as people with less income may demand less leisure. In that case, tax rate increases lead to more work effort, and the Laffer curve never slopes down. If the government does return the revenue, however, then the income effect is weaker, the substitution effect dominates, and the Laffer curve peaks and then slopes back down.

Our example does return the revenue, so we should see a hump-shaped Laffer curve. However, notice that gross-of-tax expenditure $X P_{X}$ is always 1,200, and our tax is a fraction of the gross price, so a 1 percent tax raises $R=12$, a 2 percent tax raises $R=24$, and revenue is a strictly linear function of the tax rate up to 99 percent (where $R=1,188$ ). In this case, the Laffer curve never slopes back down, at least until the tax rate hits 100 percent where revenue plummets to zero. ${ }^{14}$

Figure 1

\section{Laffer Curve, with Real Tax Revenue as a Function of the Tax Rate $t_{X}$}

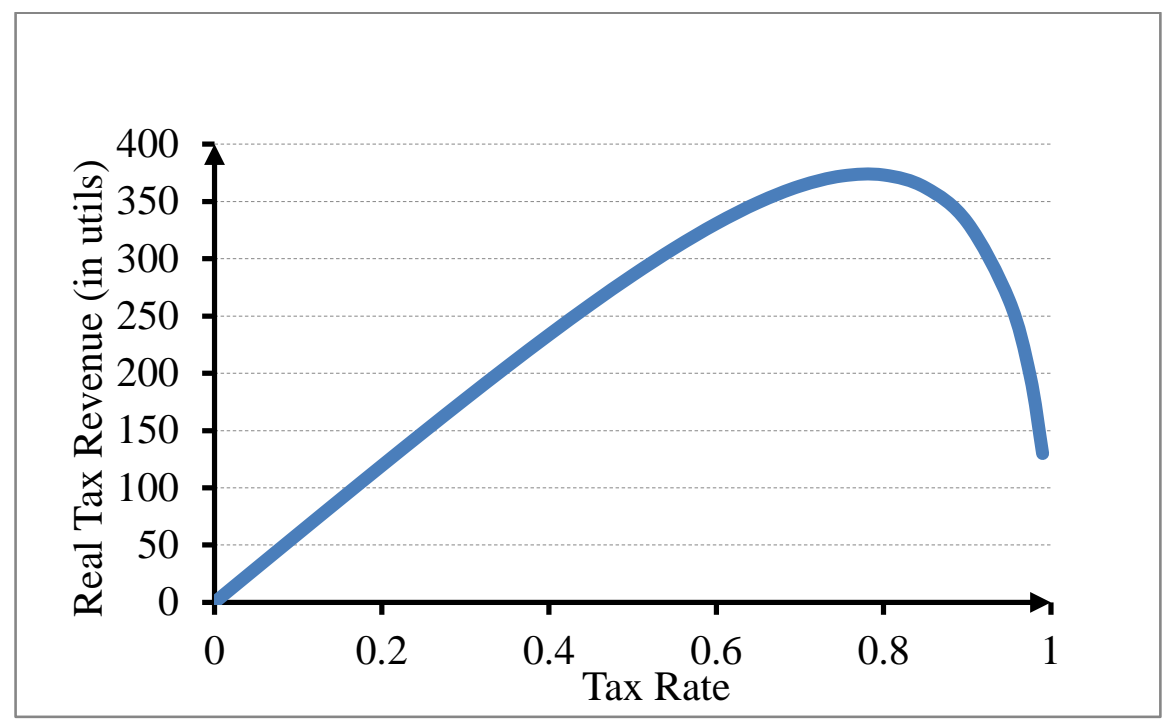

Yet, all those numbers are nominal. Income remains at 2,400, and expenditure on each good is 1,200 , even though the price index rises with the tax rate (see the values of $\overline{\boldsymbol{P}}$ in Table 2). Nominal revenue rises linearly with $t_{x}$, but those extra nominal dollars of rebate to

\footnotetext{
${ }^{14}$ In our model, a tax $\boldsymbol{t}_{\boldsymbol{X}}$ of 100 percent does not lead to a well-defined equilibrium, because the government takes all of the spending on $\boldsymbol{X}$, consumers get no $\boldsymbol{X}$, and utility is zero $\left(\boldsymbol{U}=\boldsymbol{X}^{\boldsymbol{\gamma}} \boldsymbol{Y}^{1-\boldsymbol{\gamma}}\right)$.
} 
households cannot buy as much. In this model, the best measure of "real" revenue/rebate is the amount that households can buy of the composite commodity, $U=X^{\gamma} Y^{\mathbf{1}-\gamma}$ (measured in “utils”).

That real revenue is $R / \bar{P}$, plotted in Figure 1 as a function of the tax rate $t_{X}$. This Laffer curve indeed has the normal shape. It rises steadily to a tax rate of almost 80 percent, and then falls steeply toward zero.

\section{CONCLUSION}

In a simple model with Cobb-Douglas production and utility functions, we show how to solve a CGE model on the "back of an envelope.” Using the specific example from M\&T (1975), we demonstrate how to calculate general equilibrium effects of a commodity tax on distributional incidence, deadweight loss, and marginal excess burden. We also show how CobbDouglas functions allow exact calculations of each price, output, and welfare loss. In this model, the exact calculation of excess burden is 20 percent more than the triangle approximation of Harberger (1964). We derive indirect utility, the expenditure function, equivalent variation, an exact measure of excess burden, and real revenue in a plot of the Laffer curve. 


\section{REFERENCES}

Auerbach, Alan J., and James R. Hines, 2002. "Taxation and Economic Efficiency.” In Auerbach, Alan J., and Martin Feldstein (eds.), Handbook of Public Economics, 13471421. North-Holland Publishing Company, Amsterdam, Netherlands.

Bradford, David F., 1978. "Factor Prices May be Constant but Factor Returns are Not.” Economics Letters 1 (3), 199-203.

Fullerton, Don, and Gilbert E. Metcalf, 2002. “Tax Incidence.” In Auerbach, Alan J., and Martin Feldstein (eds.), Handbook of Public Economics, 1787-1872. North-Holland Publishing Company, Amsterdam, Netherlands.

Gahvari, Firouz, 1988. “Does the Laffer Curve Ever Slope Down?” National Tax Journal 41 (2), 267-269.

Harberger, Arnold C., 1962. “The Incidence of the Corporation Income Tax.” Journal of Political Economy 70 (3), 215-240.

Harberger, Arnold C., 1964. “The Measurement of Waste.” American Economic Review 54 (3), 58-76.

Kay, John A., 1980. “The Deadweight Loss from a Tax System.” Journal of Public Economics 13 (1), 111-119.

Kimbell, Larry J., and Glenn W. Harrison, 1986. "On the Solution of General Equilibrium Models.” Economic Modelling 3 (3), 197-212.

Mas-Colell, Andreu, Michael D. Whinston, and Jerry R. Green, 1995. Microeconomic Theory. Oxford University Press, New York, NY.

Mayshar, Joram, 1990. “On Measures of Excess Burden and Their Application.” Journal of Public Economics 43 (3), 263-289.

McLure, Charles E., and Wayne R. Thirsk, 1975. “A Simplified Exposition of the Harberger Model, I: Tax Incidence.” National Tax Journal 28 (1), 1-27.

Shoven, John B., and John Whalley, 1992. Applying General Equilibrium. Cambridge University Press, Cambridge, UK.

Zodrow, George R., and John W. Diamond, 2013. “Dynamic Overlapping Generations CGE Models and the Analysis of Tax Policy: The Diamond-Zodrow Model.” In Dixon, Peter B., and Dale W. Jorgenson (eds.), Handbook of Computable General Equilibrium Modeling, 743-813. Elsevier Publishing, Amsterdam, Netherlands. 


\section{APPENDIX}

Section II provides all of the necessary background for first- or second-year graduate students to solve the exercises below. For students who have not yet seen this paper, a homework assignment can include that section plus the following six questions. An MSWord.doc that includes Section II plus the questions below is available online, so that the entire homework assignment can be modified as desired (https://dl.dropboxusercontent.com/u/35757123/Homework-Solve-CD-GE-model.docx). After reading Section II, students can be asked the following questions.

(1) Without the numerical example, use the simple Harberger model's general equations (6) and (7) to set $\boldsymbol{t}_{\boldsymbol{X}}=\mathbf{0}$ and find the incidence on the sources side of the corporate income tax $\left(t_{K X}\right)$. How much of the tax burden is borne by labor and how much by capital? Find $\bar{L} \boldsymbol{P}_{\boldsymbol{L}}{ }^{\prime}, \overline{\boldsymbol{K}} \boldsymbol{P}_{\boldsymbol{K}}$ ', and the changes in labor income and capital income.

(2) Using the numerical example, set $t_{K X}=\mathbf{0}$ and find general equilibrium incidence on the sources side of a 30 percent tax on $X$. What is the new net-of-tax wage $\left(P_{L}{ }^{\prime}\right)$ and netof-tax return to capital $\left(P_{K}{ }^{\prime}\right)$ ? Which factor bears a larger proportional burden, and why?

(3) Solve for the new use of each factor in each sector $\left(K_{X}{ }^{\prime}, L_{X}{ }^{\prime}, K_{Y}{ }^{\prime}\right.$, and $\left.L_{Y}{ }^{\prime}\right)$.

(4) One can substitute those inputs into production functions to find outputs $\left(X^{\prime}, Y^{\prime}\right)$, but nothing yet specifies the values of parameters $A$ and $B$. We know all initial equilibrium inputs to production, so first "solve backwards" for what the $A$ and $B$ parameters must have been to yield those outcomes $A=X^{0} /\left[\left(K_{X}^{0}\right)^{0.6}\left(L_{X}^{0}\right)^{0.4}\right]$, and $B=Y^{0} /\left[\left(K_{Y}^{0}\right)^{0.2}\left(L_{Y}^{0}\right)^{0.8}\right]$. (Hint: do not round off any numbers; keep all digits for the next calculation, or else rounding errors compound at each step.) Using those values, solve for the new outputs and then calculate the new output prices $\left(P_{X}{ }^{\prime}\right.$ and $\left.P_{Y}{ }^{\prime}\right)$.

(5) Insert the demand functions into the direct utility function to solve for indirect utility (a function of prices and total expenditure). Invert that expression to solve for expenditure (a function of prices and utility) and then the equivalent variation, $E V$ (MasColell, Whinston, and Green, 1995, p.82). Since the revenue from this one distorting tax on $X$ is all returned to households via lump-sum transfer in this "revenue neutral" policy package, the $E V$ measure of welfare loss to households is a measure of the excess burden of the tax. Into this expression for excess burden $(E B)$, insert the numerical solutions for prices, outputs, and utility. Calculate the $E B$ of this 30 percent tax on one output. Then divide $E B$ by revenue to calculate the average excess burden $(A E B)$. What is the meaning of this ratio?

(6) Perform all analogous calculations for a 31 percent tax on $X$. Calculate the change in excess burden, and the change in revenue. Divide the former by the latter to obtain the marginal excess burden ( $M E B$ ), defined as the change in excess burden per marginal dollar of government revenue. What is the interpretation of $M E B$, compared to $A E B$ ? 